CLINICAL STUDY

\title{
Increased adiponectin receptor-1 expression in adipose tissue of impaired glucose-tolerant obese subjects during weight loss
}

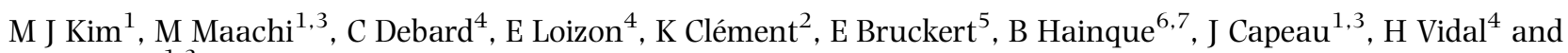 \\ J P Bastard ${ }^{1,3}$ \\ ${ }^{1}$ INSERM U-680, Faculté de Médecine, Université Pierre et Marie Curie, 75012 Paris and ${ }^{2}$ INSERM Avenir, EA 3502, Département de Nutrition, \\ Université Pierre et Marie Curie, 75004 Paris, France, ${ }^{3}$ APHP, Service de Biochimie et Hormonologie, Hôpital Tenon, 4 rue de la Chine, 75970 Paris \\ Cedex 20, France, ${ }^{4}$ UMR INSERM U-449, INRA U-1235, Faculté de Médecine, RTH Laënnec, 69372 Lyon Cedex 8, France, Services of ${ }^{5}$ Endocrinology \\ and ${ }^{6}$ Biochemistry, APHP, Hôpital Pitié-Salpêtrieére, 75013 Paris, France and ${ }^{7}$ Department of Biochemistry, UFR de Pharmacie, Université Paris V, \\ 75006 Paris, France
}

(Correspondence should be addressed to J P Bastard; Email: jean-philippe.bastard@tnn.aphp.fr)

\begin{abstract}
Objective: To investigate the mRNA expression of adiponectin, AdipoR1 and AdipoR2, the two recently cloned adiponectin receptors and peroxisome proliferator activated receptor (PPAR) $\gamma 2$ in adipose tissue of obese individuals before and during a very low calorie diet (VLCD) inducing weight loss. Methods: Twenty-three non-diabetic obese subjects with normal (NGT, $n=11$ ) or impaired glucose tolerance (IGT, $n=12$ ) (age, $47 \pm 3$ years; body mass index, $39.3 \pm 1.3 \mathrm{~kg} / \mathrm{m}^{2}$ ) were studied before and after a 3-week 3.9 MJ diet daily without exercise. mRNA levels of nine IGT and six NGT subjects were measured by real-time PCR in s.c. abdominal adipose tissue.

Results: Metabolic parameters and insulin sensitivity were improved by VLCD in the IGT group, but minimally affected in the NGT group. VLCD increased expression of AdipoR 1 in the IGT $(P=0.02)$, but not in the NGT group. Adiponectin, AdipoR2 and PPAR $\gamma 2$ mRNA levels did not change during VLCD in any group. In the IGT, but not in the NGT group, AdipoR1 and AdipoR 2 expressions were positively related to that of PPAR $\gamma 2$ and, after VLCD, AdipoR 1 and AdipoR 2 expressions were positively related to each other and to that of adiponectin.

Conclusion: In the NGT group, the 3-week VLCD inducing weight loss did not modify metabolic parameters, insulin sensitivity and the expression of the adiponectin system in adipose tissue. By contrast, in the IGT group, AdipoR1 expression increased and we found a coordinate regulation of the expression of adiponectin and its receptors. These modifications could participate, through adiponectin action on adipocytes, to the improved metabolic parameters observed in IGT subjects.
\end{abstract}

European Journal of Endocrinology 155 161-165

\section{Introduction}

Adiponectin, produced by adipose tissue, is decreased in obesity and type-2 diabetes (1). Even if its biological functions are not fully understood, it clearly plays a critical role in insulin sensitivity. Two potential adiponectin receptors, AdipoR1 and AdipoR2, have been cloned recently (2). Both are expressed in human adipose tissue (3-4). Adiponectin receptors variation has previously been studied during 8 weeks of very low calorie diet (VLCD) in obese subjects (4) and during a long diet period inducing weight loss in severely obese subjects with low value of homeostasis model assessment (HOMA) (5). However, no study has investigated adiponectin receptor expression in adipose tissue during a short period of VLCD. Furthermore, adiponectin expression was shown to be increased by thiazolidinediones in adipocytes suggesting that peroxisome proliferator-activated receptor (PPAR) $\gamma$ could be involved in the regulation of adiponectin gene expression (6). The aim of the present work was to study the effect of a weight loss induced by a 3-week VLCD on adipose tissue expression of adiponectin, AdipoR1 and AdipoR2 in obese subjects with normal (NGT) or impaired glucose tolerance (IGT) and to analyze their relationship with the expression of the transcription factor PPAR $\gamma 2$.

\section{Material and methods}

\section{Subjects}

Twenty-three Caucasian volunteers, eighteen females, and five males (age, $47 \pm 3$ years; body mass index (BMI), $39.3 \pm 1.3 \mathrm{~kg} / \mathrm{m}^{2}$ ) who participated in a VLCD program $(3.9 \pm 0.1 \mathrm{MJ} /$ day) for 21 days (7) were studied. Twelve subjects (seven females and five males) had increased 
fasting glycemia and/or IGT according to the results from the oral glucose tolerance test (OGTT). All subjects had given their written consent after being informed of the nature, purpose, and possible risks of the study. The experimental protocol was approved by the ethical committee of Assistance Publique - Hôpitaux de Paris.

\section{Methods}

After a 10-12 h overnight fast, OGTT was performed before and after 21 days of diet. Fasting samples were stored at $-80{ }^{\circ} \mathrm{C}$ for immunoassays. The measurement of glucose and insulin was performed as described previously (7). Insulin sensitivity was assessed by using HOMA calculated from fasting plasma glucose and insulin levels (fasting glucose $(\mathrm{mmol} / \mathrm{l}) \times$ fasting insulin $(\mathrm{mU} / \mathrm{l}) / 22.5)$. Insulin sensitivity was also assessed by the insulin sensitivity index (ISI) calculated using the OGTT values as proposed by Matsuda and DeFronzo as follows: ISI $=100 \quad 000 /(($ plasma glucose $(0 \mathrm{~min}) \times$ plasma insulin $(0$ min $)) \times($ plasma glucose $($ mean $) \times$ plasma insulin $($ mean $)))^{1 / 2}$, where the 'means' were calculated from concentrations obtained throughout the OGTT (8).

Serum levels of leptin and adiponectin were determined by ELISA (Quantikine leptin and adiponectin, R\&D Systems; Oxford, UK) and the adiponectin to leptin $(\mathrm{A} / \mathrm{L})$ ratio was calculated. The sensitivity of these assays was $7.8 \mathrm{pg} / \mathrm{ml}$ for leptin and $24.6 \mathrm{ng} / \mathrm{ml}$ for adiponectin. Total serum cholesterol, triglycerides and high-density lipoprotein (HDL)-cholesterol were measured by using enzymatic methods. Body composition was measured by dual X-ray absorptiometry (QDR 1000 from Hologic, Watham, MA, USA). Fat mass was determined in the truncal, arm, and leg regions, as well as at the total body level.

Subcutaneous abdominal adipose tissue biopsies were taken in six NGT and nine IGT subjects before and after
21 days of VLCD, after an overnight fast as reported previously (7). Adipose tissue samples were immediately frozen in liquid nitrogen, then total RNA was extracted with RNeasy Mini Kit (Qiagen) and stored at $-80{ }^{\circ} \mathrm{C}$ until mRNA expression analysis. The concentration of target mRNAs was measured by RT followed by realtime PCR using a LightCycler (Roche). A standard curve was systematically generated with six different amounts of purified target cDNA in the pGEMt plasmid (Promega) and each assay was performed in duplicate. The results of each mRNA were expressed as absolute concentrations, in attomoles per microgram total RNA. We also measured hypoxanthine guanine phosphoribosyl transferase (HPRT) mRNA as a reference gene so that the results are expressed as a ratio referred to the expression of HPRT.

\section{Statistical analysis}

All results are presented as mean \pm s.e.M. Non-parametric Wilcoxon test was used to compare values before and during VLCD. Differences between groups were assessed by the Mann-Whitney $U$ test. Significance of the correlations was examined using the Spearman rank correlation test. The threshold for significance was set at $P=0.05$.

\section{Results}

\section{Effect of 3-week VLCD on clinical and metabolic characteristics}

The clinical and metabolic parameters of subjects before and after VLCD are summarized in Table 1 . The subjects lost an average of $6 \%$ of initial body weight with a significant reduction of $2-3 \mathrm{~kg}$ of fat mass. In NGT

Table 1 Clinical and metabolic parameters of the obese subjects before and after 3 weeks of very low calorie diet (VLCD).

\begin{tabular}{|c|c|c|c|c|}
\hline & \multicolumn{2}{|c|}{ Normal glucose tolerance (NGT) subjects $(n=11)$} & \multicolumn{2}{|c|}{ Impaired glucose tolerance (IGT) subjects $(n=12)$} \\
\hline & Before VLCD & During VLCD & Before VLCD & During VLCD \\
\hline Age (year) & $46 \pm 4$ & & $48 \pm 4$ & \\
\hline Weight (kg) & $104 \pm 5$ & $98 \pm 4^{*}$ & $111 \pm 7$ & $104 \pm 5^{\star}$ \\
\hline Body mass index $\left(\mathrm{kg} / \mathrm{m}^{2}\right)$ & $38.9 \pm 1.4$ & $36.8 \pm 1.3^{*}$ & $39.6 \pm 2.3$ & $37.3 \pm 2.0^{*}$ \\
\hline Total fat mass $(\mathrm{kg})$ & $47.0 \pm 3.7$ & $45.1 \pm 3.6^{\star}$ & $42.6 \pm 6.1$ & $40.0 \pm 5.9^{\star}$ \\
\hline Trunk fat mass (kg) & $22.4 \pm 1.7$ & $21.3 \pm 1.6$ & $21.9 \pm 2.8$ & $19.7 \pm 3.4 \dagger$ \\
\hline Limbs fat mass $(\mathrm{kg})$ & $25.6 \pm 2.6$ & $24.4 \pm 2.4 \dagger$ & $23.0 \pm 3.3$ & $21.4 \pm 3.3$ \\
\hline Glucose $(\mathrm{mmol} / \mathrm{l})$ & $5.1 \pm 0.2$ & $4.9 \pm 0.1$ & $5.8 \pm 0.2 \ddagger$ & $5.2 \pm 0.1 \dagger$ \\
\hline Insulin (mU/l) & $11.9 \pm 2.1$ & $9.3 \pm 1.1$ & $17.4 \pm 2.2 \ddagger$ & $13.2 \pm 1.5 \dagger$ \\
\hline $\begin{array}{l}\text { Homeostasis model } \\
\text { assessment }\end{array}$ & $2.8 \pm 0.5$ & $2.1 \pm 0.3$ & $4.4 \pm 0.5 \ddagger$ & $3.0 \pm 0.3 \dagger$ \\
\hline Insulin sensitivity index & $4.6 \pm 0.8$ & $4.9 \pm 0.7$ & $2.3 \pm 0.4 \ddagger$ & $3.8 \pm 0.6 \dagger$ \\
\hline Triglycerides $(\mathrm{mmol} / \mathrm{l})$ & $1.20 \pm 0.15$ & $1.12 \pm 0.13$ & $1.99 \pm 0.28 \mp$ & $1.38 \pm 0.14 \dagger$ \\
\hline Cholesterol $(\mathrm{mmol} / \mathrm{l})$ & $5.4 \pm 0.3$ & $4.6 \pm 0.1^{*}$ & $5.9 \pm 0.3$ & $4.8 \pm 0.3^{*}$ \\
\hline HDL cholesterol $(\mathrm{mmol} / \mathrm{l})$ & $1.5 \pm 0.1$ & $1.1 \pm 0.1^{\star}$ & $1.1 \pm 0.1 \S$ & $0.9 \pm 0.1^{*}$ \\
\hline Leptin $(\mathrm{ng} / \mathrm{ml})$ & $47.6 \pm 2.9$ & $34.8 \pm 3.7^{*}$ & $37.1 \pm 4.4 \ddagger$ & $24.9 \pm 4.0^{*}$ \\
\hline Adiponectin $(\mu \mathrm{g} / \mathrm{ml})$ & $8.1 \pm 1.4$ & $6.5 \pm 1.1 \dagger$ & $5.2 \pm 0.6$ & $4.6 \pm 0.4$ \\
\hline$A / L$ & $0.191 \pm 0.049$ & $0.262 \pm 0.089$ & $0.203 \pm 0.067$ & $0.323 \pm 0.129 \dagger$ \\
\hline
\end{tabular}

${ }^{\star} P<0.01, \dagger P<0.05$; during vs before VLCD. $¥ P<0.05, \S P<0.01$; IGT vs NGT subjects before VLCD. A/L, adiponectin to leptin ratio. 
subjects, insulin sensitivity and trunk fat mass did not change significantly during VLCD, while leptin, totaland HDL-cholesterol and limb fat significantly decreased. Adiponectin levels slightly decreased, while the A/L ratio did not change during VLCD. By contrast, in IGT subjects, VLCD led to a decreased trunk fat mass and an increased insulin sensitivity as assessed either by HOMA or ISI (Table 1). The improvement in insulin resistance was associated with a reduction in fasting leptin, triglycerides, total- and HDL-cholesterol levels with no change in adiponectin levels. However, the A/L ratio significantly increased during VLCD.

\section{Effect of 3 weeks of VLCD on the expression of adiponectin, AdipoR1, AdipoR2 and PPAR $\gamma 2$ mRNA in s.c.-abdominal fat}

The mRNA expression of adiponectin, AdipoR2 and PPAR $\gamma 2$ was normalized by that of HPRT. It did not change significantly during VLCD in either NGT or IGT subjects. By contrast, the mRNA expression of AdipoR1 increased in the IGT group during VLCD $(10.0 \pm 1.8 \mathrm{vs}$ $13.9 \pm 2.6, P=0.02$; Fig. 1$)$, but not in the NGT group.

\section{Relationship between variations in gene expression induced by VLCD}

Circulating adiponectin levels were marginally correlated with adipose tissue adiponectin mRNA expression in NGT and IGT ( $r=0.493, P=0.07)$ at baseline, while no significant relationship was observed after weight loss. In the NGT group, no significant relationship was noted before or during VLCD between the parameters measured in adipose tissue. By contrast, in the IGT group, before VLCD, the mRNA expressions of AdipoR1 and AdipoR2 were positively related to that of PPAR $\gamma 2$ $(r=0.883, P<0.02 ; r=0.800, P<0.05)$ and remained marginally associated during VLCD $(P=0.09)$. During VLCD, AdipoR1 and AdipoR2 expressions were related to each other $(r=0.783, P<0.05)$ and to that of adiponectin $(r=0.883, P<0.02 ; r=0.733, P<0.05)$.

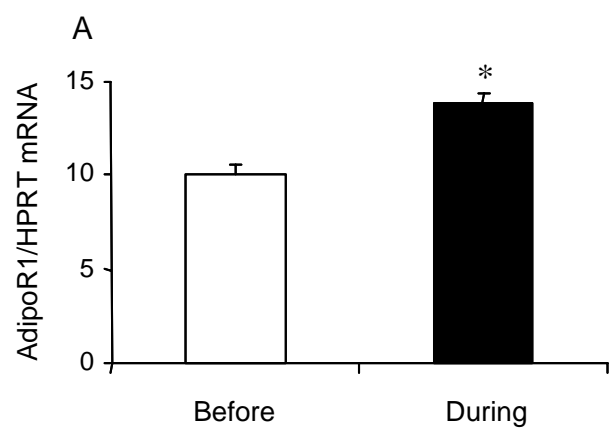

These data are in favor of the presence of a coordinate regulation of the adiponectin system in this group.

\section{Discussion}

We observed in the present study that IGT, but not NGT obese subjects improved their insulin sensitivity and metabolic parameters together with AdipoR 1 expression after a 3 -week diet inducing weight loss. In IGT subjects, insulin sensitivity improved without any change in plasma adiponectin concentration. This has previously been reported in other populations $(9,10)$. In NGT subjects, adiponectinemia was slightly decreased with no change in insulin sensitivity. Although unexpected, this is in agreement with a recent study that reported a reduced adiponectinemia in healthy volunteers during a 4-week VLCD (11). It is interesting to note that, at the metabolic level, the NGT subjects were very close to non-obese subjects studied by Wolfe and colleagues (11). Therefore, as previously suggested, it can be hypothesized that the predominant loss of s.c. instead of visceral adipose tissue could explain the decrease in adiponectin level. Accordingly, in NGT subjects, we observed no significant change in trunk fat, while limb fat was decreased. These data emphasize the fact that the relationships between changes in body weight and variations of adiponectin concentration are complex.

In most studies, weight loss of large magnitude has been related to increased circulating levels of adiponectin $(5,12)$. However, in two studies, plasma concentration or adipose tissue mRNA expression of adiponectin were not modified during a short-term VLCD with a moderate reduction of body weight $(9,10)$. Moreover, in a recent study, Abasi et al. found that insulin sensitivity improvement $(\sim 30 \%)$ in non-diabetic insulin resistant subjects under thiazolidinedione treatment during 3-4 months paralleled the increase of both total and the relative amount of several higher molecular weight adiponectin complexes (13). By contrast, these authors found that insulin sensitivity

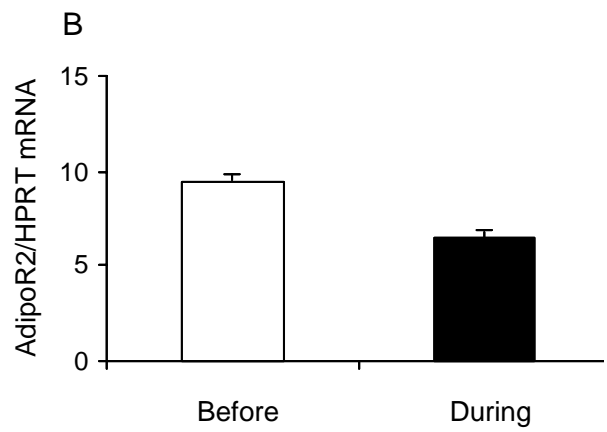

Figure 1 Variations in the mRNA expression of adiponectin receptors 1 (A) and 2 (B) normalized to that of hypoxanthine guanine phosphoribosyl transferase (HPRT) in s.c. abdominal adipose tissue of impaired glucose tolerance subjects before and during 3 weeks of very low calorie diet. ${ }^{*} P<0.05$ 
improvement of the same magnitude during caloric restriction, inducing moderate weight loss in insulinresistant obese individuals, was associated with neither circulating adiponectin concentrations nor changes in multimeric complexes (13). Indeed, adiponectin exists as a variable protein complex consisting of trimer, hexamer and larger high-molecular-weight multimers that can exert different effects in several tissues and different adiponectin assays may measure different forms of adiponectin. This may explain, at least partly, the discrepant results present in the literature on circulating adiponectin levels. Nevertheless, when we calculated the ratio of adiponectin to leptin $(\mathrm{A} / \mathrm{L})$, which was recently proposed as a relevant parameter of insulin resistance (14), we observed that it was not modified in the NGT group, but increased in the IGT group together with a decrease in trunk fat mass and an improvement in the metabolic status and insulin sensitivity. This is in accordance with the overall improvement of the metabolic status of these subjects after VLCD.

Leptin levels were higher in NGT than in IGT subjects. However, this difference did not persist when comparing female subjects in the two groups, which is in accordance with a previous study showing a close relationship between gender and leptin (15).

We observed an increased AdipoR 1 mRNA expression during VLCD in the IGT group. This result is in line with two recent reports showing that adipose tissue AdipoR 1 mRNA expression increased in obese subjects treated with VLCD for 8 weeks (4) and in type-2 diabetic subjects treated with rosiglitazone (3). By contrast, no variation was observed in the NGT group in which insulin sensitivity was not modified. This result is in accordance with the study of Bruun et al. performed in adipose tissue of slightly insulin resistant obese subjects (mean HOMA $=2.1$ before diet) after a 15-week hypocaloric diet associated with moderate physical activity (5). This suggests that AdipoR1 gene expression in adipose tissue could be modulated by metabolic factors in IGT obese subjects. It has been shown that a decreased expression of adiponectin receptors was present in the adipose tissue of obese insulin resistant mouse models and was associated with a reduction in the insulin-sensitizing effects of adiponectin suggesting that the receptors are essential to mediate adiponectin effects (16). Therefore, it can be hypothesized that the increase of AdipoR1 may enhance adiponectin binding capacities to fat cells and in turn may lead to an increase in the adiponectin effects even without any change in adiponectinemia. Otherwise, it has been shown that AMP-activated protein kinase, which is activated by adiponectin, could be involved in the regulation of lipolysis in the adipocytes $(17,18)$. It can be hypothesized that the increase in AdipoR 1 could result in enhanced adiponectin sensitivity leading to a modulation of lipolysis. Further investigations are now required to study more precisely the effects of insulin on AdipoR1 expression in adipocytes.
AdipoR2 mRNA expression did not change during VLCD in our subjects. This is in agreement with the studies of Tan et al. (3) and Rasmussen et al. (4) suggesting that different molecular mechanisms could be involved in the regulation of the two receptors.

Interestingly, adiponectin receptors were related to PPAR $\gamma 2$ expression before and marginally related after VLCD suggesting a possible relation with adipocyte differentiation and insulin sensitivity. Furthermore, the AdipoR1 and AdipoR2 expressions were related together and to that of adiponectin during VLCD, which may suggest a coordinate regulation of adiponectin and its receptors during VLCD in IGT subjects.

In summary, we show for the first time that the expression of AdipoR1 increased in human s.c.-abdominal adipose tissue of IGT obese subjects during VLCD and confirm that the two adiponectin receptors were differentially regulated under diet manipulation in obese subjects. The coordinate regulation of the adiponectin system in the adipose tissue could be involved in adiponectin action at this level and in increased insulin sensitivity. The factors and the molecular mechanisms involved in adiponectin receptors regulation require further investigations.

\section{Acknowledgements}

This work was supported by grants from Le Ministère de la Santé (Programme Hospitalier de Recherche Clinique $\left(\mathrm{N}^{\circ}\right.$ AOA94042)) and INSERM.

\section{References}

1 Kadowaki $\mathrm{T} \&$ Yamauchi T. Adiponectin and adiponectin receptors. Endocrine Review 200526 439-451.

2 Yamauchi T, Kamon J, Ito Y, Tsuchida A, Yokomizo T, Kita S, Sugiyama T, Miyagishi M, Hara K, Tsunoda M, Murakami K, Ohteki T, Uchida S, Takekawa S, Waki H, Tsuno NH, Shibata Y, Terauchi Y, Froguel P, Tobe K, Koyasu S, Taira K, Kitamura T, Shimizu T, Nagai R \& Kadowaki T. Cloning of adiponectin receptors that mediate antidiabetic metabolic effects. Nature $2003 \mathbf{4 2 3}$ 762-769.

3 Tan GD, Debard C, Funahashi T, Humphreys SM, Matsuzawa Y, Frayn KN, Karpe F \& Vidal H. Changes in adiponectin receptor expression in muscle and adipose tissue of type 2 diabetic patients during rosiglitazone therapy. Diabetologia 200548 1585-1589.

4 Rasmussen MS, Lihn AS, Perdersen SB, Bruun JM, Rasmussen M \& Richelsen B. Adiponectin receptors in human adipose tissue: effects of obesity, weight loss, and fat depots. Obesity Research 2006 $1428-35$.

5 Bruun JM, Helge JW, Richelsen B \& Stallknecht B. Diet and exercise reduce low-grade inflammation and macrophage infiltration in adipose tissue but not in skeletal muscle in severely obese subjects. American Journal of Physiology - Endocrinology and Metabolism 2006290 E961-E967.

6 Maeda N, Takahashi M, Funahashi T, Kihara S, Nishizawa H, Kishida K, Nagaretani H, Matsuda M, Komuro R, Ouchi N, Kuriyama H, Hotta K, Nakamura T, Shimomura I \& Matsuzawa Y. PPARgamma ligands increase expression and plasma concentrations of adiponectin, an adipose-derived protein. Diabetes 2001 50 2094-2099. 
7 Bastard JP, Jardel C, Bruckert E, Blondy P, Capeau J, Laville M, Vidal $\mathrm{H}$ \& Hainque B. Elevated levels of interleukin 6 are reduced in serum and subcutaneous adipose tissue of obese women after weight loss. Journal of Clinical Endocrinology and Metabolism 200085 3338-3342.

8 Matsuda M \& De Fronzo RA. Insulin sensitivity indices obtained from oral glucose tolerance testing: comparison with the euglycemic insulin clamp. Diabetes Care 199922 1462-1470.

9 Xydakis AM, Case CC, Jones PH, Hoogeveen RC, Liu MY, Smith EO, Nelson KW \& Ballantyne CM. Adiponectin, inflammation, and the expression of the metabolic syndrome in obese individuals: the impact of rapid weight loss through caloric restriction. Journal of Clinical Endocrinology and Metabolism $2004892697-2703$.

10 Garaulet M, Viguerie N, Porubsky S, Klimcakova E, Clement K, Langin D \& Stich V. Adiponectin gene expression and plasma values in obese women during very-low-calorie diet. Relationship with cardiovascular risk factors and insulin resistance. Journal of Clinical Endocrinology and Metabolism 200489 756-760.

11 Wolfe BE, Jimerson DC, Orlova C \& Mantzoros CS. Effect of dieting on plasma leptin, soluble leptin receptor, adiponectin and resistin levels in healthy volunteers. Clinical Endocrinology 200461 332-338.

12 Esposito K, Pontillo A, Di Palo C, Giugliano G, Masella M, Marfella R \& Giugliano D. Effect of weight loss and lifestyle changes on vascular inflammatory markers in obese women: a randomized trial. Journal of the American Medical Association 2003289 1799-1804.

13 Abbasi F, Chang S-A, Chu JW, Ciaraldi TP, Lamendola C, McLaughlin T, Reaven GM \& Reaven PD. Improvement in insulin resistance with weight loss, in contrast to rosiglitazone, are not associated with changes in plasma adiponectin or adiponectin multimeric complexes. American Journal of Physiology - Regulatory, Integration and Comparative Physiology 2006290 R139-R144.

14 Inoue M, Maehata E, Yano M, Taniyama M \& Suzuki S. Correlation between the adiponectin-leptin ratio and parameters of insulin resistance in patients with type 2 diabetes. Metabolism $2005 \mathbf{5 4}$ 281-286.

15 Rosenbaum M, Nicolson M, Hirsch J, Heymsfield SB, Gallagher D, Chu F \& Leibel RL. Effects of gender, body composition, and menopause on plasma concentrations of leptin. Journal of Clinical Endocrinology and Metabolism 199681 3424-3427.

16 Tsuchida A, Yamauchi T, Ito Y, Hada Y, Maki T, Takekawa S, Kamon J, Kobayashi M, Suzuki R, Hara K, Kubota N, Terauchi Y, Froguel P, Nakae J, Kasuga M, Accili D, Tobe K, Ueki K, Nagai R \& Kadowaki T. Insulin/Foxo1 pathway regulates expression levels of adiponectin receptors and adiponectin sensitivity. Journal of Biological Chemistry $200427930817-30822$.

17 Yin W, Mu J \& Birbaum MJ. Role of AMP-activated protein kinase in cyclic AMP-dependent lipolysis in 3T3-L1 adipocytes. Journal of Biological Chemistry 2003278 43074-43080.

18 Watt MJ, Holmes AG, Pinnananeni SK, Garnham AP, Steinberg GR, Kemp BE \& Febbraio MA. Regulation of HSL serine phosphorylation in skeletal muscle and adipose tissue. American Journal of Physiology - Endocrinology and Metabolism 2005290 E500-E508.

Received 23 February 2006

Accepted 28 April 2006 